\title{
Abdominal adipocyte populations in women with visceral obesity
}

\author{
Andréanne Michaud ${ }^{1,2,3}$, Sofia Laforest ${ }^{1,2,3}$, Mélissa Pelletier ${ }^{1}$, Mélanie Nadeau ${ }^{3}$, \\ Serge Simard ${ }^{3}$, Marleen Daris ${ }^{4}$, Mathieu Lebœuf ${ }^{4}$, Hubert Vidal ${ }^{5}$, Alain Géloën ${ }^{5}$ \\ and André Tchernof ${ }^{1,2,3}$ \\ ${ }^{1}$ Endocrinology and Nephrology, CHU de Quebec-Laval University, 2705 Laurier Blvd. (R-4779), Quebec City, \\ Quebec, Canada, G1V 4G2, ${ }^{2}$ School of Nutrition, Laval University, Quebec City, Quebec, Canada, ${ }^{3}$ Institut \\ universitaire de cardiologie et de pneumologie de Québec, Quebec City, Quebec, Canada, ${ }^{4}$ Gynecology Unit, \\ CHU de Québec-Laval University, Quebec City, Quebec, Canada and ${ }^{5}$ University of Lyon, CARMEN INSERM U1060, \\ INSA-Lyon, F-69621, Lyon, France
}

\author{
Correspondence \\ should be addressed \\ to A Tchernof \\ Email \\ andre.tchernof@ \\ crchudequebec.ulaval.ca
}

\section{Abstract}

Background: Visceral obesity is independently related to numerous cardiometabolic alterations, with adipose tissue dysfunction as a central feature.

Objective: To examine whether omental (OM) and subcutaneous (SC) adipocyte size populations in women relate to visceral obesity, cardiometabolic risk factors and adipocyte lipolysis independent of total adiposity.

Design and methods: OM and SC fat samples were obtained during gynecological surgery in 60 women (mean age, $46.1 \pm 5.9$ years; mean BMI, $27.1 \pm 4.5 \mathrm{~kg} / \mathrm{m}^{2}$ (range, $\left.20.3-41.1 \mathrm{~kg} / \mathrm{m}^{2}\right)$ ). Fresh samples were treated with osmium tetroxide and were analyzed with a Multisizer Coulter. Cell size distributions were computed for each sample with exponential and Gaussian function fits.

Results: Computed tomography-measured visceral fat accumulation was the best predictor of larger cell populations as well as the percentage of small cells in both OM and SC fat $(P<0.0001$ for all). Accordingly, women with visceral obesity had larger cells in the main population and higher proportion of small adipocytes independent of total adiposity $(P \leq 0.05)$. Using linear regression analysis, we found that women characterized by larger-than-predicted adipocytes in either OM or SC adipose tissue presented higher visceral adipose tissue area, increased percentage of small cells and homeostasis model assessment insulin resistance index as well as higher OM adipocyte isoproterenol-, forskolin- and dbcAMP-stimulated lipolysis compared to women with smaller-than-predicted adipocytes, independent of total adiposity $(P \leq 0.05)$.

Conclusion: Excess visceral adipose tissue accumulation is a strong marker of both adipocyte hypertrophy and increased number of small cells in either fat compartment, which relates to higher insulin resistance index and lipolytic response, independent of total adiposity.

\section{Introduction}

Excess fat accumulation on the greater omentum and mesentery has been recognized as an important predictor of cardiometabolic abnormalities such as dyslipidemia, insulin resistance and type 2 diabetes mellitus, hypertension, inflammation and a pro-thrombotic profile $(1,2,3)$. Numerous studies have now proposed visceral obesity as a marker of adipose tissue storage dysfunction and fat deposition in ectopic locations $(3,4)$. Despite the fact that overall and abdominal obesity are both related to metabolic risk, increases in adipocyte size within abdominal adipose tissue compartments may also represent a significant marker of these metabolic alterations $(5,6,7,8)$.

Adipose tissue expansion in response to a positive energy imbalance results from adipocyte hypertrophy (enlargement of existing mature adipocytes) and
(C) 2016 European Society of Endocrinology Printed in Great Britain
Published by Bioscientifica Ltd. 
adipocyte hyperplasia (recruitment of new cells and differentiation of preadipocytes) $(5,9,10)$. Thus, the total amount of body fat mass may be examined both through adipocyte size and adipocyte number. Fat cell size is influenced by various factors including sex, regional localization and obesity degree $(3,8,11,12)$. Size of cells from all anatomical localizations generally increases with obesity level $(3,5,6,12,13)$. Nevertheless, there is a wide inter-individual variability in adipocyte size at any given obesity level and values tend to reach a plateau in massively obese subjects, indicating that an increase in adipocyte number is also required for the expansion of body fat mass $(3,5,6,13)$.

Many previous studies $(5,6,14,15,16,17,18,19)$ and one recent review (8) reported that increased adipocyte size, in either the subcutaneous (SC) or visceral fat compartment, was associated with metabolic alterations and markers of adipose tissue dysfunction, independent of overall adiposity. However, in most of these studies, detailed variations in fat cell size populations were not considered (8). Osmium tetroxide fixation of adipose tissue and Multisizer Coulter analysis generate a bimodal distribution of adipocyte sizes, with a population of large adipocytes and a population of small adipocytes $(20,21)$. To our knowledge, only a few studies in humans have used this technique to examine the link between bimodal distribution of adipocyte sizes and type 2 diabetes $(22,23)$, insulin resistance $(24,25,26,27,28)$, inflammation (29) and patient response to pioglitazone (30). According to available studies, larger adipocytes and/or high proportion of small cells seem to be associated with metabolic alterations such as insulin resistance $(22,24,25,26,28)$. However, most of the studies were performed exclusively in SC adipose tissue $(22,23,24,25,28,29,30)$ and did not take into consideration visceral adipocyte size populations. Thus, how population dynamics of abdominal adipocyte size affect the pathophysiology of the metabolic alterations associated with obesity remains unclear.

Our objective was to examine whether variations in omental (OM) and SC adipocyte size distribution in women are related to visceral obesity, cardiometabolic risk factors and adipocyte lipolysis, independent of total adiposity. Considering its well-established link with adipose tissue dysfunction, we tested the hypothesis that visceral fat accumulation is a strong predictor of larger cell populations and increased percentage of small cells in both fat compartments. Furthermore, since limited expandability of adipose tissue has been proposed as a major determinant linking abdominal obesity and metabolic alterations (3), we tested the hypothesis that the presence of larger adipocytes is associated with altered cardiometabolic risk and high adipocyte lipolytic responsiveness independent of total adiposity.

\section{Subjects and methods}

\section{Participant recruitment}

We enrolled 60 women electing for total $(n=57)$ or subtotal $(n=2)$ abdominal hysterectomies or myomectomy $(n=1)$ at the CHU de Québec. A few weeks before surgery and on the morning of surgery, detailed information was obtained on medication use as well as reproductive, menstrual and medical history for each woman. Exclusion criteria were the following: i) women with Cushing syndrome, hyperthyroidism, cancer, cardiovascular diseases, type 1 or 2 diabetes and ii) women who reported significant weight loss or gain in the past year. With the exception of their gynecological condition, these women were generally healthy. Reasons for surgery included one or more of the following: menorrhagia/ menometrorrhagia $(n=29)$, myoma $(n=22)$, fibroids $(n=12)$, uterine myomatosis $(n=1)$, incapacitating dysmenorrhea $(n=6)$, pelvic pain $(n=7)$, endometriosis $(n=8)$, pelvic adhesions $(n=4)$, adenomyosis $(n=1)$ or benign cystadenoma $(n=6)$. The study was approved by the Research Ethics Committees of this institution (C0908-086). All subjects provided written informed consent to participate in the study.

\section{Anthropometrics, body composition and body fat distribution measurements}

On the morning of the surgery, body weight, height, waist circumference, resting systolic blood pressure (SBP) and diastolic blood pressure (DBP) were measured using standardized procedures. The number of criteria of the metabolic syndrome (MetS) was assessed for each woman as follows: i) waist circumference $\geq 88 \mathrm{~cm}$; ii) plasma triglycerides $>1.69 \mathrm{mmol} / \mathrm{l}$; iii) HDL-cholesterol $\leq 1.29 \mathrm{mmol} / \mathrm{l}$; iv) SBP $\geq 130 \mathrm{mmHg}$ or $\mathrm{DBP} \geq 85 \mathrm{mmHg}$ and v) fasting glycemia $\geq 5.6 \mathrm{mmol} / \mathrm{l}$. MetS + women had to meet three or more criteria, as described by the National Cholesterol Education Program (NCEP) Adult Treatment Panel III (ATP III) (31). Body fat distribution and body composition measurements were performed a few days before surgery ( $14 \pm 13$ days), according to standardized protocols. These measurements were performed after a 12 h-overnight fast. Abdominal SC and visceral adipose tissue cross-sectional areas at the L4-L5 vertebrae level 
were determined by computed tomography using a GE Light Speed 1.1 CT Scanner (General Electric Medical Systems, Milwaukee, WI, USA). Briefly, subjects were examined in the supine position, with arms stretched above the head. Images from scans were used for the quantification of total abdominal adipose tissue area using an attenuation range of -190 to -30 Hounsfield Units. Visceral adipose tissue area was measured by delineating the intra-abdominal cavity at the internal-most aspect of the abdominal and oblique muscle walls surrounding the cavity and the posterior aspect of the vertebral body. SC adipose tissue area was obtained by subtracting visceral adipose tissue area from total abdominal area. Regions of interest were delineated with the ImageJ $1.33 \mathrm{u}$ Software (National Institutes of Health, Bethesda, MD, USA). All analyses were performed by the same investigator. Intraobserver coefficients of variation were 0.3 and $1.3 \%$ for total, SC and visceral adipose tissue area respectively. Total body fat mass, trunk fat mass and lean body mass were assessed by a dual energy X-ray absorptiometry (Hologic QDR-4500A densitometer with whole-body fan beam software v8.26a:3; Hologic, Inc., Bedford, MA, USA).

\section{Plasma lipid profile and glucose homeostasis measurements}

Fasting blood samples were collected on the morning of surgery after a 12 h-overnight fast. From these samples, cholesterol and triglyceride levels in both plasma and lipoprotein fractions were measured as previously described (32). Glucose was measured with a Modular P800 System (Roche Diagnostics). Insulin was measured by ELISA (Alpco, Salem, NH, USA). Homeostasis model assessment insulin resistance $\left(\mathrm{HOMA}_{\mathrm{ir}}\right)$ index was calculated from fasting glucose and insulin levels (33).

\section{Adipose tissue sampling}

SC and OM adipose tissue samples were collected during the surgical procedure at the site of incision and at the distal portion of the greater omentum respectively. The samples were immediately carried to the laboratory.

\section{Adipose cell size distribution measurements}

Fresh tissue samples ( $\sim 50 \mathrm{mg}$ ) were fixed in collidineHCL osmium tetroxide solution for at least $96 \mathrm{~h}$ at room temperature. Samples were then rinsed with $\mathrm{NaCl} 0.9 \%$ for $24 \mathrm{~h}$, incubated with $8 \mathrm{M}$ urea for $48 \mathrm{~h}$ and rinsed with PBS $0.01 \%$ Triton X-100. The resulting fixed cells were analyzed using a Beckman Coulter Multisizer IV (Beckman Coulter, Villepinte, France) as previously described (34). The range of cell sizes analyzed was $25-240 \mu \mathrm{m}$. Cell size distributions were determined with at least 12000 cells/sample and were analyzed by fitting an exponential (small cells)-Gaussian (large adipocytes) formula (nonlinear least-squares function) as described by McLaughlin et al. (24). Endpoints of interest in the cell populationderived parameters were the mode (center of the Gaussian peak), which is the median diameter of the large cells, the height and the width of the Gaussian distribution as well as the nadir, which is the least probable cell size (in frequency) between the two cell populations, and the percentage of small cells defined as the percentage of adipose cells below the frequency nadir. We also calculated from these distributions the mean diameter of the $10 \%$ larger cells.

\section{Adipocyte isolation and adipocyte lipolysis measurement}

Adipocytes were isolated with collagenase digestion in Krebs-Ringer-Henseleit (KRH) buffer for $45 \mathrm{~min}$ at $37^{\circ} \mathrm{C}$ according to a modified version of the Rodbell method (12). For lipolysis experiments, cell suspensions were incubated for $2 \mathrm{~h}$ at $37^{\circ} \mathrm{C}$ in $\mathrm{KRH}$ buffer, with or without $\beta$-adrenergic receptor agonist isoproterenol $\left(10^{-10}\right.$ $\left.10^{-5} \mathrm{~mol} / \mathrm{l}\right)$, post-receptor-acting agents dbcAMP $\left(10^{-3} \mathrm{~mol} / \mathrm{l}\right)$ or forskolin $\left(10^{-5} \mathrm{~mol} / \mathrm{l}\right)$. Glycerol release in the medium was measured by bioluminescence with the NAD-linked bacterial luciferase assay as described (12). Lipid weight of the cell suspension was measured using Dole's extraction. Data were expressed in $\mu \mathrm{mol} / 10^{6}$ cells per $2 \mathrm{~h}(12,14)$.

\section{Statistical analysis}

Quantitative analysis of cell population-derived parameters was performed by mathematical modeling using SAS Software V9.4 (SAS Institute, Carry, NC, USA). Student's paired $t$-tests were computed to examine regional differences in adipocyte size distribution parameters $(n=54)$. Pearson correlation coefficients were computed to assess associations between adipocyte size distribution parameters, age, body fatness, body fat distribution and cardiometabolic risk. Partial Pearson correlation coefficients were computed to assess associations between adipocyte size distribution parameters and cardiometabolic risk after statistical adjustments for BMI. Multiple linear regressions were performed to identify the 
best predictor of the mode, nadir, height, width, $10 \%$ larger cells and percentage of small cells in the OM or SC adipose tissues. These regression models included age, BMI, total body fat mass, menopausal status, VAT area and SAT area. To identify participants with visceral obesity, a separate linear regression analysis was computed to predict visceral fat accumulation using BMI. The subjects were then stratified in two subgroups according to the residuals of this regression. Women with a positive residual were considered as having higher-than-predicted visceral fat accumulation for a given BMI, and women with a negative residual were considered as having lowerthan-predicted visceral fat accumulation for a given BMI. Such stratification generated two subgroups of women matched for BMI but with either low or high VAT area. There was no significant difference between the two subgroups for total body fat mass, age and SAT area, even if these variables were not included in the regression model. Student's $t$-tests were used to compare women with vs without visceral obesity. Furthermore, an independent linear regression analysis was performed to predict the mode in each fat compartment separately using BMI to control for total adiposity $(5,6)$. In each fat compartment, women with a positive residual were considered as having larger-than-predicted mode value for a given BMI, whereas women with a negative residual were considered as having smaller-than-predicted mode value for a given BMI. Using this stratification, we obtained two subgroups of women matched for overall adiposity but with either a large or small mode in each adipose tissue compartment. There was no significant difference between the two subgroups for total body fat mass, age, menopausal status and SAT area, even if these variables were not included in the models. In each fat compartment, $t$-tests were used to compare adipocyte size distribution parameters, $\mathrm{HOMA}_{\text {ir }}$ index as well as isolated adipocyte lipolysis between the two subgroups of women. $t$-tests were also performed to compare adipocyte size distribution parameters, adiposity variables and metabolic alterations between MetS + or MetS - women. Non-normally distributed variables were $\log _{10^{-}}$or Box-Cox-transformed. Statistical analyses were performed using JMP Software (SAS Institute).

\section{Results}

\section{Clinical characteristics of participants}

The average age of the women was 46.1 years and they were slightly overweight with a mean BMI of $27.1 \mathrm{~kg} / \mathrm{m}^{2}$ (Table 1). The women exhibited a wide range of adiposity
Table 1 Characteristics of the 60 women of the study.

\begin{tabular}{l} 
Variables \\
\hline Age (years) \\
Waist circumference $(\mathrm{cm})$ \\
BMI $\left(\mathrm{kg} / \mathrm{m}^{2}\right)$ \\
Total body fat mass $(\mathrm{kg})$ \\
Trunk fat mass $(\mathrm{kg})$ \\
Trunk fat mass/total body \\
fat mass \\
Adipose tissue area $\left(\mathrm{cm}^{2}\right)^{\mathrm{a}}$ \\
Total \\
Subcutaneous \\
Visceral \\
Plasma lipid profile \\
Cholesterol (mmol/l) \\
Total \\
VLDL \\
LDL \\
HDL \\
Triglycerides (mmol/l) \\
Cholesterol/HDL-cholesterol \\
Glucose homeostasis \\
Fasting glucose $(\mathrm{mmol} / \mathrm{l})$ \\
Fasting insulin $(\mu \mathrm{IU} / \mathrm{ml})^{\mathrm{b}}$ \\
HOMA index
\end{tabular}

\begin{tabular}{|c|c|}
\hline Mean \pm s.D. & Range (min-max) \\
\hline $46.1 \pm 5.9$ & $35.2-59.3$ \\
\hline $92 \pm 11$ & 68-124 \\
\hline $27.1 \pm 4.5$ & $20.3-41.1$ \\
\hline $25.2 \pm 6.9$ & $9.6-47.3$ \\
\hline $11.6 \pm 4.0$ & $3.3-24.1$ \\
\hline $0.5 \pm 0.1$ & $0.3-1.1$ \\
\hline $407 \pm 140$ & $92-725$ \\
\hline $311 \pm 103$ & 71-568 \\
\hline $97 \pm 45$ & $21-278$ \\
\hline $4.92 \pm 0.82$ & $3.21-6.99$ \\
\hline $0.40 \pm 0.27$ & $0.05-1.23$ \\
\hline $3.06 \pm 0.76$ & $1.65-4.94$ \\
\hline $1.46 \pm 0.39$ & $0.83-2.57$ \\
\hline $1.12 \pm 0.55$ & $0.40-3.32$ \\
\hline $3.53 \pm 0.89$ & $2.01-6.15$ \\
\hline $5.3 \pm 0.4$ & $4.5-6.6$ \\
\hline $7.3 \pm 4.0$ & $1.5-21.4$ \\
\hline $1.7 \pm 1.0$ & $0.3-4.9$ \\
\hline
\end{tabular}

VLDL, very-LDL; HOMA index, homeostasis model assessment index. ${ }^{\mathrm{a}} n=59$.

${ }^{\mathrm{b}} n=58$.

values (the spectrum from lean to obese), as shown by BMI values spanning from 20.3 to $41.1 \mathrm{~kg} / \mathrm{m}^{2}$. According to BMI categories of the World Health Organization, 24 women were lean, 22 women were overweight and 14 women were obese. These women also displayed a large range of body fat distribution as shown by ranges of trunkto-total body fat mass ratio and adipose tissue areas.

\section{Regional differences in adipocyte populations of abdominal adipose tissues}

Bimodal distributions were found for all the samples examined, with a population of large adipocytes corresponding to the Gaussian distribution and a population of small adipocytes corresponding to cells below the frequency nadir and the exponential curve fit. Figure 1A shows OM and SC mean adipocyte size bimodal distributions, which is the mean relative frequency for each cell size diameter. Adipocyte size distributions from the $\mathrm{OM}$ compartment were different from those of the SC compartment, showing a shift to the right for SC adipocyte populations. According to parameters obtained from the distributions, the mode $(P \leq 0.001$; Fig. $1 \mathrm{~B})$, the $10 \%$ larger cells $(P \leq 0.0001$, data not shown), the width $(P \leq 0.0001$, data not shown) and the nadir of the 

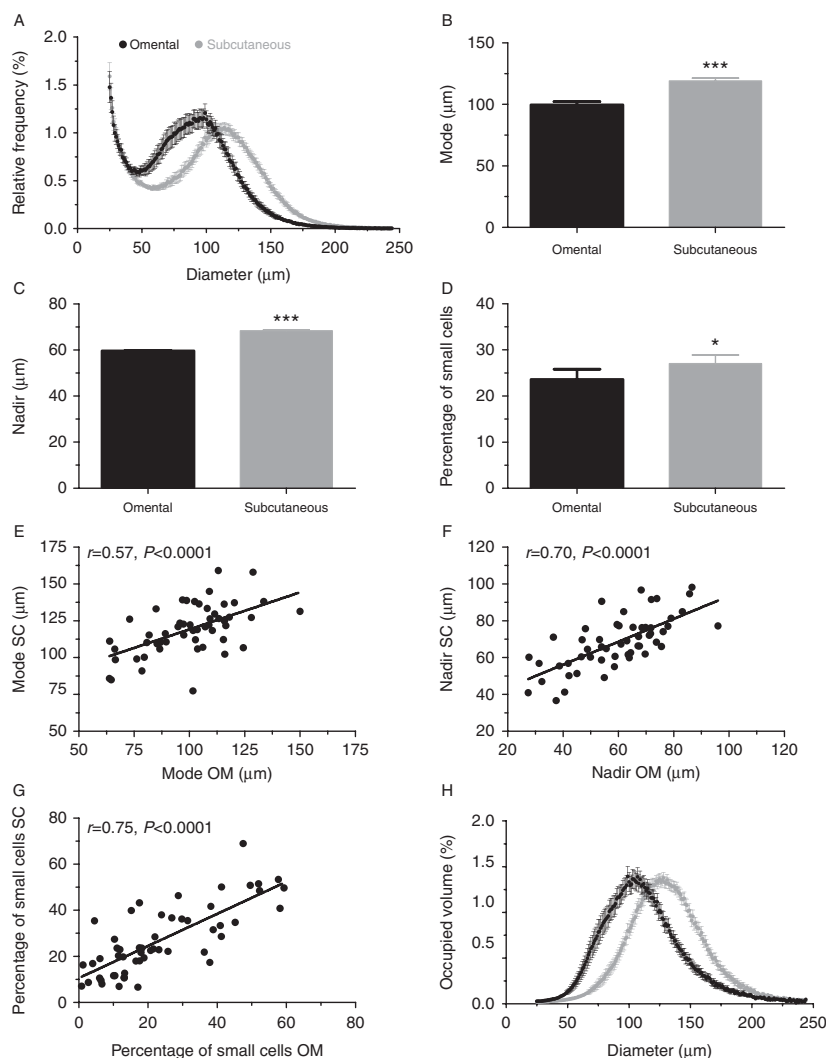

\section{Figure 1}

Comparison of adipocyte size bimodal distribution parameters between SC and OM adipose tissue $(n=54)$. (A) Mean cell size distribution curves obtained from raw data (which is the mean relative frequency for each cell size diameter $(25-240 \mu \mathrm{m}) \pm$ S.E.M.), (B) mode of the fitted-distribution, (C) nadir of the fitteddistribution and (D) percentage of small cells in OM and SC adipose tissue. Means \pm s.E.M. are shown $* P \leq 0.05$ and $* * * P \leq 0.001$. (E) Correlations between the mode of large cells in $\mathrm{OM}$ adipose tissue and the mode of large cells in SC adipose tissue. (F) Correlations between the nadir of the distribution in OM adipose tissue and the nadir of the distribution in SC adipose tissue; and (G) correlations between the percentage of small cells in OM adipose tissue and the percentage of small cells in SC adipose tissue. Pearson correlation coefficients and

$P$ values are shown. (H) Mean cell size distribution curves expressed as percentage of the volume occupied at cell size diameter (25-240 $\mu \mathrm{m}) \pm$ s.E.M. (B, C, D, E, F and G) Cell populationderived parameters were obtained by mathematical modeling.

distributions $(P \leq 0.001)$ (Fig. $1 \mathrm{C})$ as well as the percentage of small cells $(P \leq 0.05$; Fig. 1D) were all significantly higher in SC compared to OM fat samples. The height of the distribution was significantly lower in SC compared to OM fat samples ( $P \leq 0.0001$, data not shown). Strong positive correlations were observed between OM and SC adipose tissue for the mode $(r=0.57, P<0.0001)$, the nadir $(r=0.70, P<0.0001)$ as well as the proportion of small cells $(r=0.75, P<0.0001)$ (Fig. 1E, F and G). When mean cell size distribution curves were expressed as percentage of the volume occupied for each cell diameter (Fig. 1H), we observed that the volume occupied by the population of small cells was negligible (very low) despite the large number of these cells.

Figure 2 illustrates associations between the mode, nadir or percentage of small cells in both OM and SC depots. Highly significant positive correlations were observed between the mode and nadir of the distributions in both adipose tissue compartments ( $P<0.0001$ for both). In addition, the mode and nadir were positively and significantly associated with the percentage of small cells in both fat depots $(P<0.0001$ for all). Size of the $10 \%$ larger cells was also positively and significantly related to the nadir, mode and percentage of small cells in both fat depots $(P<0.0001$ for all, data not shown). The height of
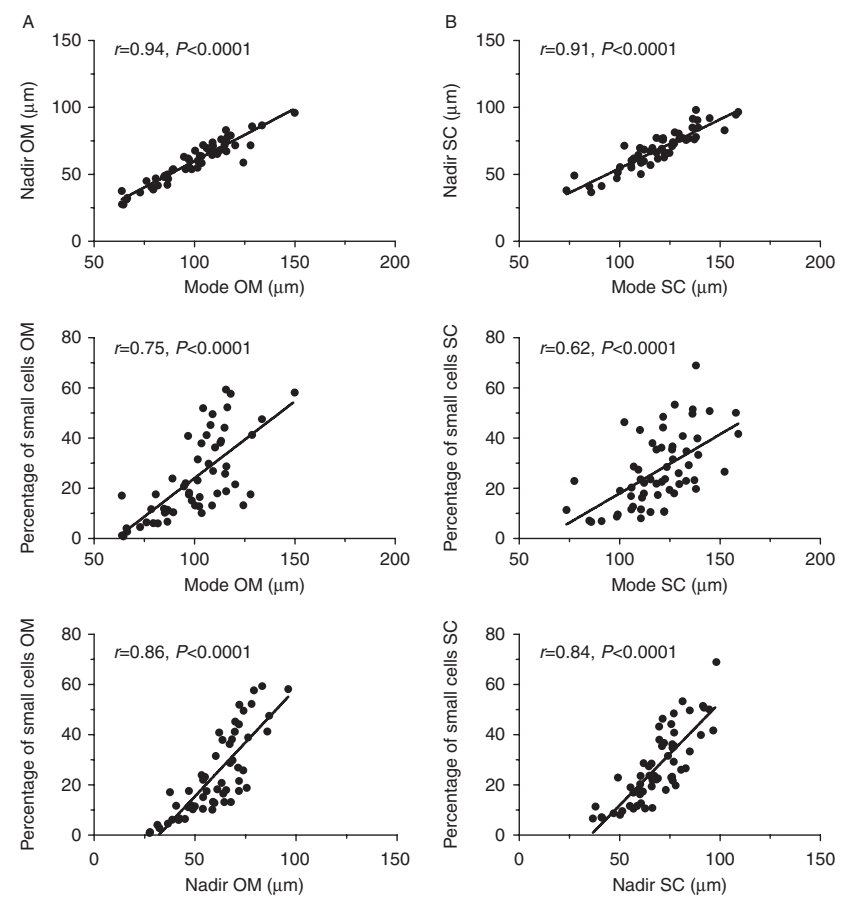

Figure 2

Correlations between the mode of large adipocyte populations, the nadir of the distribution or the percentage of small cells in OM $(n=55 ; \mathrm{A})$ or SC $(n=59 ; \mathrm{B})$ adipose tissues. Pearson correlation coefficients and $P$ values are shown. 
the Gaussian distribution was negatively correlated with the nadir, mode, $10 \%$ larger cells and percentage of small cells in both fat depots $(P<0.0001$ for all, data not shown).

\section{Adipocyte populations in relation with body fatness or visceral obesity}

Table 2 shows Pearson correlation coefficients between $\mathrm{OM}$ and SC adipocyte size distribution parameters and age or body fatness (BMI and total body fat mass) and body fat distribution measurements (computed tomographyderived adipose tissue areas). No significant association was found between age and adipocyte size distribution parameters. Increased weight, waist circumference, BMI, total body fat mass and computed tomography-derived adipose tissue areas were strongly associated with larger cells of the main population (mode and 10\% larger cells), larger nadir size and greater percentage of small cells in both fat compartments $(P \leq 0.05)$. Inversely, increased weight, BMI, waist circumference, total body fat mass as well as computed tomography-measured adipose tissue areas were related to lower height of the main cell population in both adipose tissue compartments $(P \leq 0.05)$. The width of the Gaussian in both depots was positively and significantly correlated with waist circumference and measurements of body fat distribution $(P \leq 0.05)$. Overall, increased adiposity variables were associated with enlargement of larger cells, lower height of the main cell population and greater percentage of small cells. Similar patterns of correlations were observed in each BMI category (lean, overweight and obese).

To identify the strongest predictors of adipocyte size distribution parameters in both depots, multiple linear regression models were computed. Regression models included VAT area, SAT area, total body fat mass, BMI, age and menopausal status (Table 3). VAT area was the best correlate of the mode, nadir, percentage of small cells, $10 \%$ larger cells, height and width of the Gaussian curve in $\mathrm{OM}$ adipose tissue, explaining respectively $62.1 \%$ $(P<0.0001), 63.6 \%(P<0.0001), 43.9 \%(P<0.0001)$, $45.8 \% \quad(P<0.0001), 34.2 \% \quad(P<0.0001)$ and $17.1 \%$ $(P=0.002)$ of the variance (data not shown for the $10 \%$ larger cells, the height and width). Interestingly, VAT area was also the best predictor of the mode, nadir, percentage of small cells, $10 \%$ larger cells, peak height and width in the SC depot, explaining respectively, $43.7 \%$ $(P<0.0001), 41.5 \%(P<0.0001), 23.6 \%(P<0.0001)$, $39.2 \%(P<0.0001), \quad 24.8 \%(P<0.0001)$ and $12.3 \%$ $(P=0.008)$ of the variance (data not shown for the $10 \%$ larger cells, peak height and width).

To better examine cell populations in visceral obesity, women were stratified in two subgroups according to the residuals of the regression between VAT area and BMI. Such stratification generated two subgroups of women matched for overall adiposity but with either low $(n=28)$ or high $(n=31)$ VAT area (Fig. 3A and B). No significant

Table 2 Pearson correlation coefficients between OM and SC adipocyte size bimodal distribution parameters and age or adiposity measurements.

\begin{tabular}{|c|c|c|c|c|c|c|}
\hline Variables & Mode & $10 \%$ larger cells & Width & Height & Nadir & $\begin{array}{c}\text { Percentage of } \\
\text { small cells }\end{array}$ \\
\hline \multicolumn{7}{|l|}{ Omental adipose tissue } \\
\hline Age & -0.15 & -0.13 & -0.18 & 0.03 & -0.05 & 0.03 \\
\hline Weight & $0.56^{\S}$ & $0.48^{\ddagger}$ & $0.24^{\dagger}$ & $-0.31^{\dagger}$ & $0.58^{\S}$ & $0.39^{\ddagger}$ \\
\hline Waist circumference & $0.65^{\S}$ & $0.57^{\S}$ & $0.34^{\dagger}$ & $-0.47^{\S}$ & $0.66^{\S}$ & $0.51^{\S}$ \\
\hline BMI & $0.55^{\S}$ & $0.44^{\ddagger}$ & 0.19 & $-0.25^{\dagger}$ & $0.54^{\S}$ & $0.32^{\dagger}$ \\
\hline Total body fat mass & $0.63^{\S}$ & $0.52^{\S}$ & $0.23 *$ & $-0.30^{\dagger}$ & $0.64^{\S}$ & $0.42^{\ddagger}$ \\
\hline Total adipose tissue area & $0.71^{\S}$ & $0.59^{\S}$ & $0.36^{\ddagger}$ & $-0.46^{\S}$ & $0.69^{\S}$ & $0.52^{\S}$ \\
\hline Visceral adipose tissue area & $0.77^{\S}$ & $0.66^{\S}$ & $0.40^{\ddagger}$ & $-0.58^{\S}$ & $0.77^{\S}$ & $0.65^{\S}$ \\
\hline SC adipose tissue area & $0.63^{\S}$ & $0.55^{\S}$ & $0.35^{\dagger}$ & $-0.42^{\ddagger}$ & $0.61^{\S}$ & $0.45^{\S}$ \\
\hline \multicolumn{7}{|l|}{ Subcutaneous adipose tissue } \\
\hline Age & -0.01 & 0.10 & $0.22 *$ & -0.12 & -0.08 & -0.01 \\
\hline Weight & $0.56^{\S}$ & $0.46^{\ddagger}$ & $0.22 *$ & $-0.34^{\ddagger}$ & $0.56^{\S}$ & $0.35^{\ddagger}$ \\
\hline Waist circumference & $0.65^{\S}$ & $0.56^{\S}$ & $0.32^{\dagger}$ & $-0.49^{\S}$ & $0.64^{\S}$ & $0.47^{\S}$ \\
\hline BMI & $0.59^{\S}$ & $0.46^{\ddagger}$ & $0.26^{\dagger}$ & $-0.36^{\ddagger}$ & $0.55^{\S}$ & $0.33^{\dagger}$ \\
\hline Total body fat mass & $0.63^{\S}$ & $0.52^{\S}$ & $0.30^{\dagger}$ & $-0.40^{\ddagger}$ & $0.60^{\S}$ & $0.39^{\ddagger}$ \\
\hline Total adipose tissue area & $0.68^{\S}$ & $0.58^{\S}$ & $0.34^{\ddagger}$ & $-0.47^{\S}$ & $0.65^{\S}$ & $0.44^{\S}$ \\
\hline Visceral adipose tissue area & $0.65^{\S}$ & $0.62^{\S}$ & $0.34^{\ddagger}$ & $-0.48^{\S}$ & $0.63^{\S}$ & $0.47^{\S}$ \\
\hline SC adipose tissue area & $0.65^{\S}$ & $0.52^{\S}$ & $0.31^{\dagger}$ & $-0.45^{\S}$ & $0.62^{\S}$ & $0.42^{\ddagger}$ \\
\hline
\end{tabular}


Table 3 Multiple linear regression analysis for mode, nadir and \% of small cells in SC and OM adipose tissues. Regression models included age, BMI, total body fat mass, visceral adipose tissue area, subcutaneous adipose tissue area and menopausal status.

\begin{tabular}{|c|c|}
\hline Dependent variables & Independent variables \\
\hline \multicolumn{2}{|l|}{ Model 1} \\
\hline Mode OM & $\begin{array}{l}\text { Visceral adipose tissue area } \\
\text { Age } \\
\text { Menopausal status }\end{array}$ \\
\hline \multicolumn{2}{|l|}{ Model 2} \\
\hline Nadir OM & Visceral adipose tissue area \\
\hline \multicolumn{2}{|l|}{ Model 3} \\
\hline Percentage of small cell OM & $\begin{array}{l}\text { Visceral adipose tissue area } \\
\text { BMI } \\
\text { Subcutaneous adinose tissue area }\end{array}$ \\
\hline \multicolumn{2}{|l|}{ Model 4} \\
\hline Mode SC & $\begin{array}{l}\text { Visceral adipose tissue area } \\
\text { Subcutaneous adipose tissue area }\end{array}$ \\
\hline \multicolumn{2}{|l|}{ Model 5} \\
\hline Nadir SC & $\begin{array}{l}\text { Visceral adipose tissue area } \\
\text { Subcutaneous adipose tissue area } \\
\text { Age }\end{array}$ \\
\hline \multicolumn{2}{|l|}{ Model 6} \\
\hline Percentage of small cell SC & Visceral adipose tissue area \\
\hline
\end{tabular}

\begin{tabular}{|c|c|c|}
\hline Partial $\left(r^{2} \times 100\right)$ & Total $\left(r^{2} \times 100\right)$ & $P$ values \\
\hline 62.11 & 65.38 & $<0.0001$ \\
\hline 1.98 & & NS \\
\hline 1.29 & & NS \\
\hline 63.58 & 63.58 & $<0.0001$ \\
\hline 43.85 & 49.42 & $<0.0001$ \\
\hline $\begin{array}{l}3.45 \\
2.12\end{array}$ & & $\begin{array}{c}0.08 \\
\text { NS }\end{array}$ \\
\hline 43.65 & 50.44 & $<0.0001$ \\
\hline 6.79 & & 0.01 \\
\hline 41.54 & 49.30 & $<0.0001$ \\
\hline 5.39 & & 0.02 \\
\hline 2.37 & & NS \\
\hline 23.59 & 23.59 & $<0.0001$ \\
\hline
\end{tabular}

difference was found between women with vs those without visceral obesity in BMI $\left(26.9 \pm 4.4 \mathrm{~kg} / \mathrm{m}^{2}\right.$ vs $27.4 \pm 4.5 \mathrm{~kg} / \mathrm{m}^{2}$, respectively, $\left.P=0.66\right)$, total body fat mass $(24.3 \pm 7.7 \mathrm{~kg}$ vs $26.1 \pm 6.3 \mathrm{~kg}$, respectively, $P=0.32)$, age ( $45.6 \pm 5.2$ years vs $47.9 \pm 6.5$ years, respectively, $P=0.17)$ and SAT area $\left(291 \pm 101 \mathrm{~cm}^{2}\right.$ vs $328 \pm$ $103 \mathrm{~cm}^{2}$, respectively, $P=0.16$ ). As expected from the stratification model, VAT area was significantly higher in women with than those without visceral obesity $(120 \pm$ $45 \mathrm{~cm}^{2}$ vs $71 \pm 33 \mathrm{~cm}^{2}$, respectively, $P \leq 0.0001$ ). Women with visceral obesity had significantly larger cells of the main population (mode and 10\% larger cells; Fig. 3C and D), larger nadir size (Fig. 3E) as well as greater percentage of small cells (Fig. 3F) in both adipose tissue depots $(P \leq 0.05)$, independent of overall adiposity. Differences between the two subgroups were more significant in the OM fat compartment $(P \leq 0.001$ for all). Height of the Gaussian curve in both fat depots was significantly lower in women with visceral obesity ( $P \leq 0.01$, data not shown). Regional differences in adipocyte size distribution curves were observed between the two subgroups. Although no significant depot difference was observed for the percentage of small cells $(P=0.37)$ in visceral obese women, this percentage was significantly higher in SC compared to OM fat in women without visceral obesity $(P=0.002)$. The mode, size of the $10 \%$ larger cells and nadir were higher in the SC vs OM depot in both subgroups $(P \leq 0.01$ for all), whereas height of the distribution was significantly lower in SC compared to OM fat samples $(P \leq 0.0001)$. As expected, women with visceral obesity had higher fasting glucose $(5.13 \pm 0.36 \mathrm{mmol} / \mathrm{l}$ vs $5.48 \pm$ $0.45 \mathrm{mmol} / \mathrm{l}, \quad P=0.002)$, fasting insulin $(6.47 \pm$ $4.40 \mu \mathrm{IU} / \mathrm{ml}$ vs $7.89 \pm 3.62 \mu \mathrm{IU} / \mathrm{ml}, P=0.06)$ and $\mathrm{HOMA}_{\mathrm{ir}}$ index $(1.49 \pm 1.05$ vs $1.91 \pm 0.87, P=0.03)$ compared to women with low visceral fat accumulation (data not shown).

\section{Adipocyte populations in relation with cardiometabolic risk factors}

Strong correlations were observed between metabolic alterations and adipocyte size distribution parameters in each depot (Table 4). Larger cells of the main population (mode and nadir) and greater percentage of small cells in both depots were associated with higher values of plasma triglycerides, cholesterol-to-HDL-cholesterol ratio and $\mathrm{HOMA}_{\text {ir }}$ index $(P \leq 0.05$ for all, except a trend between values of plasma triglycerides and the mode in the SC depot, $P<0.10$ ). These cell size distribution parameters were also negatively related to concentrations of HDLcholesterol $(P \leq 0.05)$. The distribution width and size of the $10 \%$ larger cells in both depots were also negatively associated with values of HDL-cholesterol $(P \leq 0.05)$. In $\mathrm{OM}$ adipose tissue only, the width of the distribution and size of the $10 \%$ larger cells were positively associated with concentrations of plasma triglycerides and $\mathrm{HOMA}_{\text {ir }}$ index 

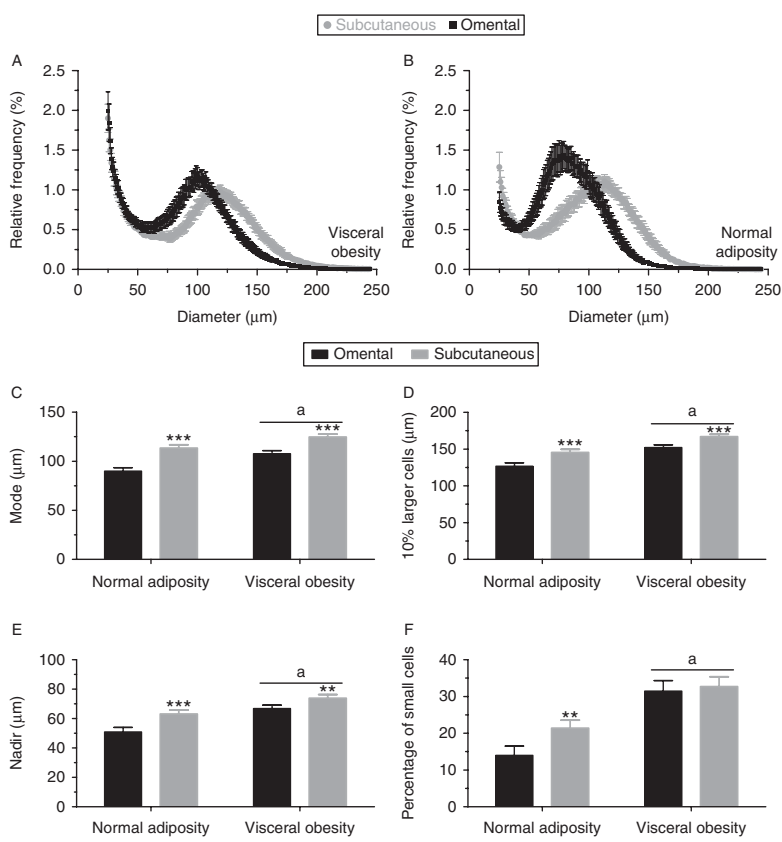

\section{Figure 3}

Comparison of OM and SC adipocyte size bimodal distribution parameters between women characterized by visceral $(n=31$; A) or normal adiposity $(n=28 ; \mathrm{B})$, but with similar overall adiposity. Means \pm S.E.M. are shown $* * P \leq 0.01$ and $* * * P \leq 0.001$, ${ }^{a}$ significant difference between women characterized by normal vs visceral adiposity $(P \leq 0.01)$. (C, D, E and F) Cell population-derived parameters were obtained by mathematical modeling.

$(P \leq 0.05)$. In both depots, size of the $10 \%$ larger cells was also positively related to the total-to-HDL-cholesterol ratio $(P \leq 0.05)$. Inversely, higher height of the main distribution in both fat compartments was correlated with lower concentrations of plasma triglycerides, totalto-HDL-cholesterol ratio and $\mathrm{HOMA}_{\mathrm{ir}}$ index as well as higher values of HDL-cholesterol $(P \leq 0.05$ for all, except a trend between values of plasma triglycerides and height in the SC depot, $P<0.10)$. Statistical adjustment for BMI did not substantially change these associations (Table 4). When associations were examined within each BMI category, we found similar patterns of correlations than those presented in Table 4. Overall, OM adipocyte size distribution parameters were most strongly associated with $\mathrm{HOMA}_{\text {ir }}$ index, whereas SC adipocyte size distribution parameters were most strongly associated with values of HDL-cholesterol.

To further examine the link between adipocyte populations and cardiovascular risk factors, women were stratified in two subgroups according to the presence (MetS + ) or the absence (MetS-) of MetS. As expected, MetS + women were characterized by altered cardiometabolic risk factors and increased adiposity. In both fat compartments, MetS + women $(n=17)$ were characterized by larger mode (OM: $111.4 \pm 15.7 \mu \mathrm{m}$ vs $96.0 \pm 18.5 \mu \mathrm{m}$, $P=0.008$ and SC: $133.1 \pm 15.8 \mu \mathrm{m}$ vs $113.7 \pm 15.5 \mu \mathrm{m}$, $P<0.0001)$, larger nadir (OM: $70.4 \pm 14.8 \mu \mathrm{m}$ vs $52.2 \pm$ $14.1 \mu \mathrm{m}, P=0.003$ and SC: $80.6 \pm 11.2 \mu \mathrm{m}$ vs $63.8 \pm$ $12.6 \mu \mathrm{m}, P<0.0001)$, larger $10 \%$ largest cells (OM: $151.1 \pm 19.8 \mu \mathrm{m}$ vs $132.0 \pm 24.6 \mu \mathrm{m}, P=0.009$ and SC: $175.7 \pm 18.0 \mu \mathrm{m}$ vs $153.7 \pm 17.3 \mu \mathrm{m}, P<0.0001)$, lower Gaussian peak height (OM: $1.4 \pm 0.5$ vs $1.9 \pm 0.7, P=0.01$ and SC: $1.0 \pm 0.2$ vs $1.4 \pm 0.3, P<0.0001)$ and a greater proportion of small cells (OM: $34.5 \pm 16.5 \%$ vs $20.4 \pm$ $14.9 \%, P=0.005$ and SC: $39.3 \pm 13.6 \%$ vs $22.1 \pm 11.6 \%$, $P<0.0001)$ compared to MetS - women $(n=43)$. Statistical adjustment for BMI did not markedly change the differences between the two subgroups.

Table 4 Pearson correlation coefficients between OM or SC adipocyte sizes bimodal distribution parameters and metabolic alterations.

\begin{tabular}{l}
\hline Variables \\
\hline Omental adipose tissue \\
HDL-cholesterol \\
Plasma triglycerides \\
Total-to-HDL cholesterol ratio \\
HOMA ir index \\
Subcutaneous adipose tissue \\
HDL-cholesterol \\
Plasma triglycerides \\
Total-to-HDL cholesterol ratio $_{\text {HOMA }_{\text {ir }} \text { index }}$
\end{tabular}

\begin{tabular}{c}
\hline Mode \\
\hline \\
$-0.37^{\ddagger}$ \\
$0.31^{\dagger}$ \\
$0.38^{\ddagger}$ \\
$0.49^{\S, a}$ \\
$-0.43^{\S, a}$ \\
$0.19^{\star}$ \\
$0.42^{\S}$ \\
$0.28^{\dagger}$ \\
\hline
\end{tabular}

\begin{tabular}{c}
$\begin{array}{c}10 \% \text { larger } \\
\text { cells }\end{array}$ \\
\hline \\
$-0.36^{\ddagger}$ \\
$0.28^{\dagger}$ \\
$0.36^{\ddagger}$ \\
$0.44^{\ddagger, a}$ \\
$-0.41^{\dagger, a}$ \\
$0.17^{\ddagger, a}$ \\
$0.45^{\ddagger}$ \\
$0.23^{*}$ \\
\hline
\end{tabular}

\begin{tabular}{c}
\hline Width \\
\hline$-0.31^{\dagger}$ \\
$0.32^{\dagger, a}$ \\
$0.25^{\star}$ \\
$0.44^{\ddagger, a}$ \\
$-0.31^{\dagger, a}$ \\
-0.06 \\
$0.27^{\dagger}$ \\
0.01 \\
\hline
\end{tabular}

\begin{tabular}{c}
\hline Height \\
\hline $0.37^{\ddagger, a}$ \\
$-0.38^{\ddagger, a}$ \\
$-0.39^{\ddagger, a}$ \\
$-0.47^{\S, a}$ \\
$0.52^{\S, a}$ \\
$-0.22^{\star}$ \\
$-0.52^{\S, a}$ \\
$-0.29^{\dagger}$ \\
\hline
\end{tabular}

\begin{tabular}{cccc}
\hline Nadir & & $\begin{array}{c}\text { Percentage of } \\
\text { small cells }\end{array}$ \\
\cline { 1 - 1 }$-0.32^{\dagger}$ & & $-0.30^{\dagger}$ \\
$0.32^{\dagger}$ & & $0.35^{\ddagger, a}$ \\
$0.42^{\ddagger, a}$ & & $0.40^{\ddagger, a}$ \\
$0.46^{\S, a}$ & & $0.47^{\S, a}$ \\
& & \\
$-0.47^{\S, a}$ & & $-0.47^{\S, a}$ \\
$0.30^{\dagger}$ & & $0.31^{\dagger}$ \\
$0.46^{\S}$ & & $0.44^{\S, a}$ \\
$0.43^{\S, a}$ & & $0.47^{\S, a}$ \\
\hline
\end{tabular}

${ }^{\star} P<0.10,{ }^{\dagger} P<0.05,{ }^{\ddagger} P<0.01$ and ${ }^{\S} P<0.001$.

Remained significant after adjustment for BMI. 


\section{Adipocyte populations in relation to adipocyte lipolysis independent of total adiposity}

To examine whether OM and SC adipocyte hypertrophy are related to adipocyte lipolysis measurements independent of total adiposity, women were stratified in two subgroups according to residuals of the regression between the mode of the large cell population and BMI. For each fat depot, women with a positive residual were considered as having larger-than-predicted mode value for a given BMI, whereas women with a negative residual were considered as having smaller-than-predicted mode value for a given BMI. Such stratification generated two subgroups of women with either large or small mode values of the main cell population, but matched for total adiposity (Figs 4 and 5).

Figure 4A shows mean OM adipocyte size distribution curves of these subgroups. The two curves were markedly different, showing a shift to the right for OM cell size distributions in women characterized by larger-thanpredicted $\mathrm{OM}$ adipocytes. As expected from the stratification model, women with larger-than-predicted OM adipocytes had significantly larger mode in OM adipose tissue $(P \leq 0.0001$; Fig. 4B). These women also had a higher nadir ( $P \leq 0.0001$; Fig. $4 \mathrm{~B})$, higher mean size of the $10 \%$ larger cells $(P \leq 0.0001$; Fig. $4 \mathrm{~B})$, lower height of the main distribution $(P \leq 0.0001$, data not shown $)$ and greater percentage of small cells in $\mathrm{OM}$ adipose tissue $(P \leq 0.0001)$ (Fig. 4C), as well as higher $\mathrm{HOMA}_{\text {ir }}$ index $(P=0.002$; Fig. 4D) and higher OM adipocyte isoproterenol- $\left(10^{-10}-10^{-5} \mathrm{~mol} / \mathrm{l}\right)$, forskolin- and dbcAMPstimulated lipolysis $(P \leq 0.05)$ (Fig. $4 \mathrm{E}$ and $\mathrm{F}$ ) compared to women characterized by smaller-than-predicted OM adipocytes, independent of overall adiposity.

Very similar results were observed when women were stratified according to SC adipocyte sizes (Fig. 5). The two mean adipocyte size distribution curves were different, showing a shift to the right in women with larger-thanpredicted SC adipocytes (Fig. 5A). As expected, women characterized by larger-than-predicted SC adipocytes had significantly larger mode, nadir and size of $10 \%$ larger cells in SC adipose tissue $(P \leq 0.0001$ for all; Fig. $5 \mathrm{~B})$. These women also had greater percentage of small cells in SC adipose tissue $(P=0.001$; Fig. $5 \mathrm{C})$, lower height of the main distribution $(P \leq 0.0001)$, higher $\mathrm{HOMA}_{\mathrm{ir}}$ index $(P=0.06$; Fig. 5D), higher SC adipocyte basal as well as isoproterenol- $\left(10^{-10}-10^{-5} \mathrm{~mol} / \mathrm{l}\right)$, forskolin- and dbcAMP-stimulated lipolysis $(P \leq 0.05)$ (Fig. $5 \mathrm{E}$ and $\mathrm{F}$ ) compared to women characterized by smaller-thanpredicted SC adipocytes, independent of overall adiposity.
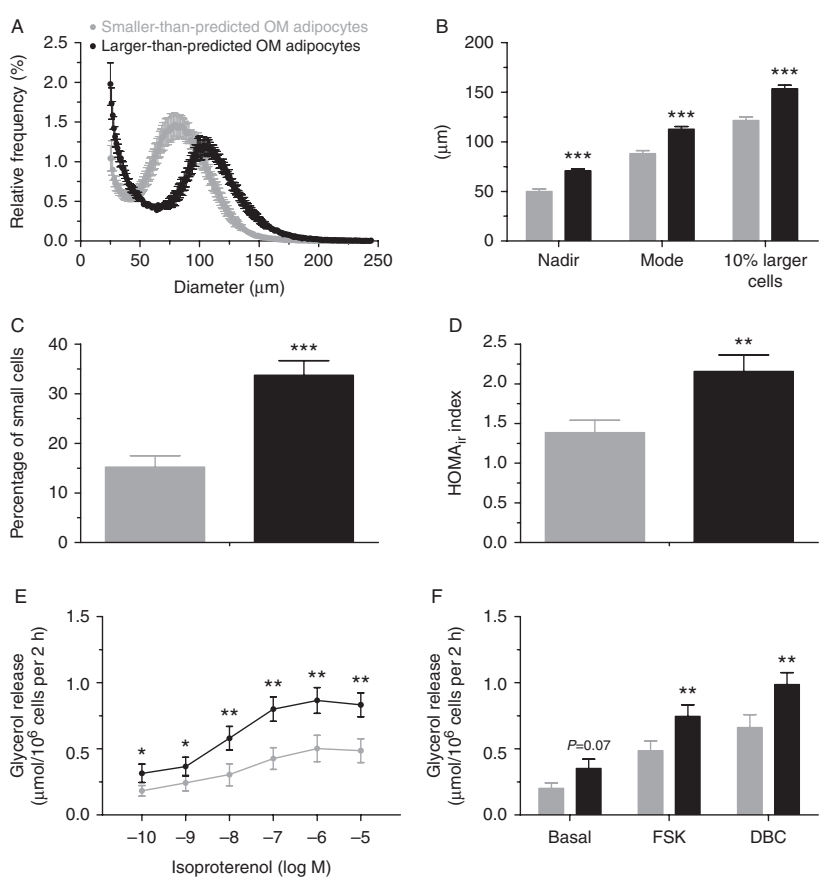

\section{Figure 4}

Comparison of OM adipocyte size bimodal distribution parameters (A, B and C), HOMA $A_{\text {ir }}$ index (D) and isolated OM adipocyte lipolysis ( $E$ and $F$ ) in women characterized by larger( $n=26)$ or smaller- $(n=29)$ than-predicted OM adipocytes, but similar overall adiposity. No significant difference was found between subgroups for BMI $\left(27.0 \pm 4.8 \mathrm{~kg} / \mathrm{m}^{2}\right.$ vs $27.3 \pm 4.4 \mathrm{~kg} / \mathrm{m}^{2}$, respectively, $P=0.76$ ), total body fat mass $(25.6 \pm 6.0 \mathrm{~kg}$ vs $24.8 \pm 7.6 \mathrm{~kg}$, respectively, $P=0.65)$, age (47.6 \pm 6.5 years vs $47.3 \pm 4.6$ years, respectively, $P=0.82)$ and SAT area $\left(318 \pm 92 \mathrm{~cm}^{2}\right.$ vs $305 \pm 108 \mathrm{~cm}^{2}$, respectively, $P=0.66)$. VAT area was significantly higher in women with larger-than-predicted compared to those with smallerthan-predicted OM adipocytes $\left(118 \pm 48 \mathrm{~cm}^{2}\right.$ vs $83 \pm 35 \mathrm{~cm}^{2}$, respectively, $P=0.002$ ). ( $B$ and $C$ ) Cell population-derived parameters were obtained by mathematical modeling. DBC, post-receptor-acting agent dbcAMP $\left(10^{-3} \mathrm{~mol} / \mathrm{l}\right)$; FSK, postreceptor-acting agent forskolin $\left(10^{-5} \mathrm{~mol} / \mathrm{l}\right)$. Means \pm s.E.M. are shown $* P \leq 0.05, * * P \leq 0.01$ and $* * * P \leq 0.001$.

\section{Discussion}

The main objective of the present study was to examine whether variations in $\mathrm{OM}$ and SC adipocyte size distributions in women are related to visceral obesity, cardiometabolic risk factors and adipocyte lipolysis independent of total adiposity. Using osmium tetroxide fixation of adipose tissue and Multisizer Coulter analysis, we demonstrated that adipocyte size distributions from the OM 

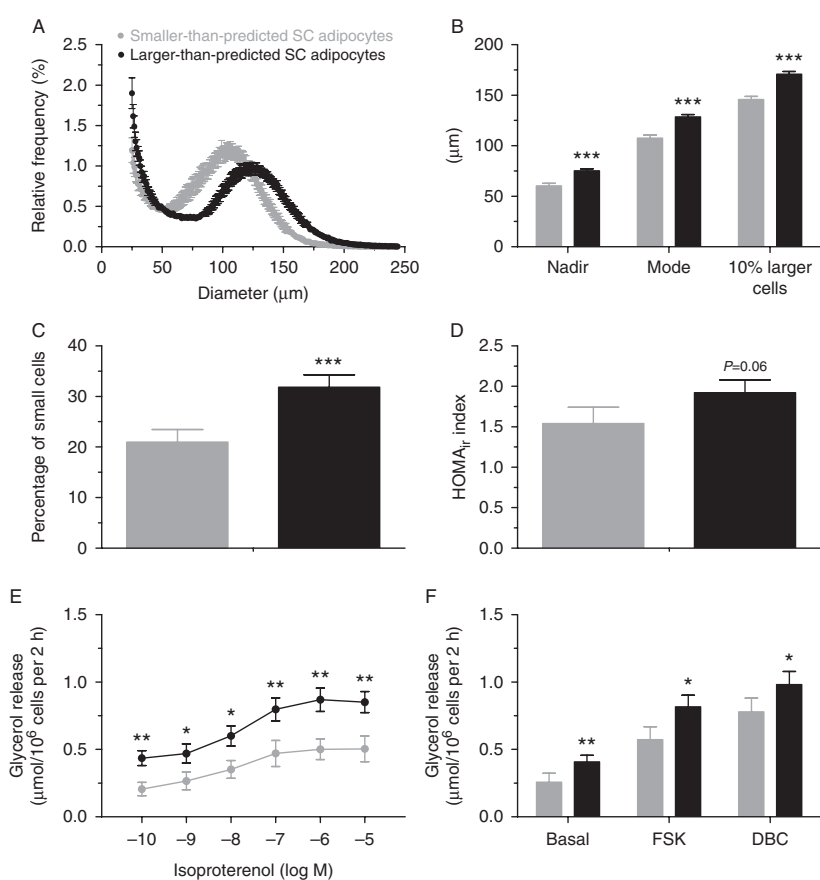

\section{Figure 5}

Comparison of SC adipocyte size bimodal distribution parameters ( $A, B$ and C), HOMA $\mathrm{Hr}_{\text {ir }}$ index (D) and isolated SC adipocyte lipolysis ( $E$ and $F$ ) in women characterized by larger( $n=33$ ) or smaller- $(n=26)$ than-predicted SC adipocytes, but similar overall adiposity. No significant difference was found between subgroups for BMI $\left(26.7 \pm 4.2 \mathrm{~kg} / \mathrm{m}^{2}\right.$ vs $27.7 \pm 4.8 \mathrm{~kg} / \mathrm{m}^{2}$, respectively, $P=0.41$ ), total body fat mass $(25.1 \pm 6.0 \mathrm{~kg}$ vs $25.3 \pm 8.3 \mathrm{~kg}$, respectively, $P=0.65)$, age ( $46.8 \pm 6.3$ years vs $46.5 \pm 5.3$ years, respectively, $P=0.85$ ) and SAT area $\left(311 \pm 101 \mathrm{~cm}^{2}\right.$ vs $309 \pm 110 \mathrm{~cm}^{2}$, respectively, $\left.P=0.94\right)$ (data not shown). A trend was observed for higher VAT area in women characterized by larger-than-predicted SC adipocytes $\left(103 \pm 47 \mathrm{~cm}^{2}\right.$ vs $87 \pm 42 \mathrm{~cm}^{2}$, respectively, $\left.P=0.10\right)$. (B and $\left.C\right)$ Cell population-derived parameters were obtained by mathematical modeling. DBC, post-receptor-acting agent dbcAMP $\left(10^{-3} \mathrm{~mol} / \mathrm{l}\right)$; FSK, post-receptor-acting agent forskolin $\left(10^{-5} \mathrm{~mol} / \mathrm{l}\right)$. Means \pm s.E.M. are shown $* P \leq 0.05$, $* * P \leq 0.01$ and $* * * P \leq 0.001$.

compartment were significantly different from those of the SC compartment. Furthermore, strong correlations were observed between parameters of adipocyte size distributions in both depots and adiposity measurements. As shown with our regression analyses, visceral fat accumulation was the best predictor of all parameters of the larger cell distributions as well as the percentage of small cells in both OM and SC fat. Accordingly, we also demonstrated that women with visceral obesity had significantly larger cells and lower height of the main population as well as higher proportion of small cells in both adipose tissue compartments, independent of total adiposity. Using linear regression analysis, we found that women with larger-than-predicted adipocytes in either OM or SC adipose tissue presented higher VAT area and were characterized by increased percentages of small cells and $\mathrm{HOMA}_{\mathrm{ir}}$ index as well as a high adipocyte lipolytic responsiveness compared to women with smaller-thanpredicted adipocytes, independent of total adiposity.

The relationship between adipocyte size populations assessed with osmium tetroxide and glucose homeostasis has been investigated in a few studies $(22,24,25,26,28$, 30). More specifically, McLaughlin et al. (24) originally demonstrated that mean fat cell size of the larger SC cells was not significantly different between insulin resistant and insulin sensitive patients. In the latter study, they also showed that insulin resistance in obese subjects was associated with higher percentage of small cells in SC adipose tissue (24). In a more recent study, the same group demonstrated that insulin resistance was related to both enlargement of large adipocytes and increased proportion of small adipose cells in SC adipose tissue, independent of body fat mass and sex (25). The authors suggested that the small number of patients in the first study may explain the discrepancy observed between these reports (25). In the current analysis, we also found that both hypertrophic adipocytes and higher percentage of small cells in OM and SC fat depots were strongly associated with blood lipid and glucose homeostasis alterations. Statistical adjustment for BMI did not markedly change the strongest associations. To support this finding, women with the MetS were characterized by increased adiposity variables, altered lipid profile and glucose homeostasis as well as enlargement of larger adipocytes, lower height of the Gaussian distribution and greater percentage of small cells. Consistent with the results of McLaughlin et al. (25), we demonstrated using a linear regression analysis that women with large adipocytes in either OM or SC depot are characterized by increased small cell numbers and insulin resistance, as well as high adipocyte lipolytic responsiveness compared to women with smaller-than-predicted adipocytes, independent of total adiposity. Consistently, Pasarica et al. (22) previously demonstrated that patients with type 2 diabetes mellitus had larger adipocytes and lower total adipocyte number, but a greater proportion of small cells compared to BMI-matched obese subjects. Taken together, these data suggest an important effect of adipocyte cellularity independent of obesity level. McLaughlin et al. (24) were the first group to propose that these small 
adipocytes below the frequency nadir represent immature adipocytes that are unable to correctly store excess energy $(24,25)$. We also observed that even if obese women had an increased proportion of small cells and larger adipocytes of the main population, the volume occupied by the small cells was very low, suggesting that these cells may not significantly contribute to the storage of triglycerides. Thus, higher proportion of small adipocytes and hypertrophic mature adipocytes may both be markers of impaired adipogenesis, which is known to be involved in insulin resistance. Further studies are clearly needed to characterize the function of these small adipocytes and their impact on metabolic disease risk.

The notion that adipocyte size increases as a function of obesity levels is now well supported in the literature $(3,8)$. Our findings that the mode of adipocyte size distributions increases with overall and regional adiposity measurements are expected and consistent with this concept. We also found that with increasing adiposity level, enlargement of larger adipocytes (mode and size of $10 \%$ larger cells) was associated with higher nadir, lower height of the Gaussian distribution as well as greater percentage of small cells, suggesting that the shape of the distribution is influenced by obesity level. The physiological meaning of these results is complex to interpret. Only a portion of the large adipocytes seem to be able to expand their size to reach extreme values of the distribution (35). Various factors may explain the inability of some adipocytes to further expand through hypertrophy such as angiogenesis, extra-cellular matrix remodeling, hypoxia or inflammation $(8,32,36)$.

Our analysis also demonstrated that VAT area was the strongest predictor of both hypertrophic adipocytes of the large cell population and percentage of small cells in both fat compartments. Using linear regression analysis, we consistently reported that women with high VAT area were characterized by larger cells of the main population as well as higher percentage of small cells in both adipose tissue depots compared to women with low VAT area, independent of total adiposity. The difference in VAT area between women characterized by larger- and smaller-thanpredicted adipocyte (especially in OM adipose tissue) also supports these findings. In agreement with our results, Kursawe et al. (27) demonstrated that adolescents with high VAT accumulation, according to the ratio of VAT to VAT + SAT, were characterized by higher proportion of small adipose cells, hypertrophy of the largest cells and lower expression of adipogenesis and lipogenesis genes in SC adipose tissue compared to adolescents with low VAT. Taken together, these findings suggest that excess visceral fat accumulation may be an important predictor of hypertrophy of the cells and increased number of small cells either in the SC and OM fat compartment. These results are consistent with the notion that excess visceral adipose tissue accumulation is a strong marker of dysfunctional adipose tissue and limited capacity of adipose tissues to store excess of energy, which can lead to ectopic fat deposition and metabolic alterations $(1,8,12,32,37)$.

A few studies also reported that fat cell size seems to be a marker of altered adipocyte lipid metabolism $(3,8,14,15$, 19). Previous studies reported that large adipocytes were characterized by higher rates of glycerol release compared to smaller adipocytes from the same fat compartment (15, 38). Our study was not designed to compare adipocyte function between small adipocytes and large adipocytes. Nevertheless, our study demonstrated that lipolytic response to $\beta$-adrenergic receptor agonist stimulation was increased in women with larger-than-predicted adipocytes independent of total adiposity. Consistent with our results, Laurencikiene et al. (19) reported that large adipocytes had increased hormone-induced lipolysis rates and protein expression of hormone-sensitive lipase, perilipin and adipose triglyceride lipase compared to small adipocytes in SC adipose tissue. Furthermore, in a previous sample of women, we also demonstrated that women with adipocyte hypertrophy in either OM or SC adipose tissues, had higher adipocyte lipolytic responses and had altered adipose tissue expression of genes involved in lipid storage, inflammation and angiogenesis (14). Our results highlighted once again the concept that hypertrophied adipocytes are more lipolytic compared to smaller and more abundant adipocytes, which may reflect the link between adipocyte hypertrophy, altered lipid handling and the development of insulin resistance.

Previous studies demonstrated that OM mean adipocyte size was lower (around 20\%) compared to SC adipocyte size in women, while this depot difference was not observed in men $(3,8)$. These studies support our results in women showing that the mode, size of the $10 \%$ larger cells, the nadir and the percentage of small cells were all lower in OM compared to $\mathrm{SC}$ fat samples. To our knowledge, only one study also reported OM and SC differences in cell size parameters using detailed analysis of adipose cell size distributions (26). Consistent with our findings, they demonstrated in 11 obese insulin resistant women that the peak diameter of large cells and nadir between the two cell populations were significantly lower in $\mathrm{OM}$ compared to $\mathrm{SC}$ adipose tissue. However, they found that the percentage of small cells was similar between the two tissue depots (26). In our sample, 
women with visceral obesity showed no significant regional difference for the percentage of small cells which is consistent with these previous findings.

Limitations of the study should be acknowledged. We cannot conclude on cause-and-effect relationships as our results are cross-sectional. However, we investigated a relatively large number of women for who we obtained visceral/SC adipose tissue samples. These women were also very well-characterized for body fatness and body fat distribution. Our study only included women because of the difficulty to perform similar studies in lean-to-moderately obese men. Strengths of the study included the quantitative method used to measure adipocyte size which allowed the characterization of large and very small fat cells. Other groups have clearly demonstrated the existence of small cells in human adipose tissue $(18,24)$. However, to discriminate mature adipocytes and artefacts, fat cells under $25 \mu \mathrm{m}$ were not considered in our analysis (8). Even if our results are consistent with the notion that impaired adipogenesis may contribute to the development of metabolic complications, additional studies are needed to better understand the mechanisms involved in adipose tissue lipid storage.

In conclusion, our results support the hypothesis that excess visceral fat accumulation is the best predictor of both larger adipocytes and increased percentage of small adipocytes in $\mathrm{OM}$ and SC adipose tissues. Women with largerthan-predicted adipocytes in either OM or SC adipose tissue have greater percentage of small adipocytes, higher insulin resistance index and higher adipocyte lipolytic responsiveness, independent of total adiposity. On the basis of these results and other studies of our group $(3,32,37)$, excess visceral adipose tissue accumulation, adipocyte hypertrophy and increased proportion of small adipocytes, in both OM and SC adipose tissues, seem to represent strong markers of dysfunctional adipose tissue and limited capacity of adipose tissues to store excess dietary energy.

Declaration of interest

A Tchernof is a recipient of research grant support from Johnson \& Johnson Medical Companies for studies unrelated to this manuscript. Other authors have no conflicts of interest.

\section{Funding}

The study was supported by operating funds from the Canadian Institutes of Health Research-Institute of Gender and Health to A Tchernof (MOP102642). A Michaud is the recipient of a scholarship from Fonds de Recherche du Québec-Santé. S Laforest is the recipient of studentships from the Canadian Institute of Health Research (Frederick Banting and Charles Best Canada Graduate Scholarships).
Author contribution statement

A Michaud performed the experiment; analyzed and interpreted the data; wrote the manuscript; critically revised the manuscript and gave final approval. S Laforest performed analysis and interpretation of data; critically revised the manuscript and gave final approval. M Pelletier performed the experiment; critically revised the the manuscript and gave final approval. M Nadeau performed the experiment; critically revised the manuscript and gave final approval. S Simard performed statistical analysis of data; critically revised the manuscript and gave final approval. M Daris was responsible for medical coverage; supervision of clinical aspects of the study; sample acquisition; critical revision of the manuscript; final approval. M Lebœuf provided medical coverage, supervision of clinical aspects of the study, sample acquisition, critical revision of the manuscript and for final approval. $\mathrm{H}$ Vidal contributed to the analysis and interpretation of data, critical revision of the manuscript and for final approval. A Géloën performed the experiment; contributed to data collection and analysis, interpretation of data, manuscript writing, critical revision of the manuscript and gave final approval. A Tchernof was responsible for funding, design and conduction of the study; data collection and analysis; interpretation of data; manuscript writing; critical revision of the manuscript; final approval and study supervision.

\section{Acknowledgements}

We would like to acknowledge the contribution of the gynecologists, nurses and radiology technicians at $\mathrm{CHU}$ de Québec-Laval University Research Center as well as the collaboration of participants. We would also like to acknowledge the technical contribution of Lilas Hadji and Véronique Pierre for these experiments.

\section{References}

1 Despres JP \& Lemieux I. Abdominal obesity and metabolic syndrome. Nature 2006444 881-887. (doi:10.1038/nature05488)

2 Lemieux I, Couillard C, Pascot A, Bergeron N, Prud'homme D, Bergeron J, Tremblay A, Bouchard C, Mauriege P \& Despres JP. The small, dense LDL phenotype as a correlate of postprandial lipemia in men. Atherosclerosis 2000153 423-432. (doi:10.1016/S0021-9150(00)00424-X)

3 Tchernof A \& Despres JP. Pathophysiology of human visceral obesity: an update. Physiological Reviews 201393 359-404. (doi:10.1152/ physrev.00033.2011)

4 Despres JP. Excess visceral adipose tissue/ectopic fat the missing link in the obesity paradox? Journal of the American College of Cardiology 2011 57 1887-1889. (doi:10.1016/j.jacc.2010.10.063)

5 Arner E, Westermark PO, Spalding KL, Britton T, Ryden M, Frisen J, Bernard S \& Arner P. Adipocyte turnover: relevance to human adipose tissue morphology. Diabetes 201059 105-109. (doi:10.2337/db09-0942)

6 Veilleux A, Caron-Jobin M, Noel S, Laberge PY \& Tchernof A. Visceral adipocyte hypertrophy is associated with dyslipidemia independent of body composition and fat distribution in women. Diabetes 201160 1504-1511. (doi:10.2337/db10-1039)

7 Bays HE, Gonzalez-Campoy JM, Bray GA, Kitabchi AE, Bergman DA Schorr AB, Rodbard HW \& Henry RR. Pathogenic potential of adipose tissue and metabolic consequences of adipocyte hypertrophy and increased visceral adiposity. Expert Review of Cardiovascular Therapy 20086 343-368. (doi:10.1586/14779072.6.3.343)

8 Laforest S, Labrecque J, Michaud A, Cianflone K \& Tchernof A. Adipocyte sizes as a determinant of metabolic disease and adipose tissue dysfunction. Critical Reviews in Clinical Laboratory Sciences 2015 52 301-313. (doi:10.3109/10408363.2015.1041582)

9 Spalding KL, Arner E, Westermark PO, Bernard S, Buchholz BA, Bergmann O, Blomqvist L, Hoffstedt J, Naslund E, Britton T et al. 
Dynamics of fat cell turnover in humans. Nature $2008 \mathbf{4 5 3} 783-787$. (doi:10.1038/nature06902)

10 Drolet R, Richard C, Sniderman AD, Mailloux J, Fortier M, Huot C, Rheaume C \& Tchernof A. Hypertrophy and hyperplasia of abdominal adipose tissues in women. International Journal of Obesity 200832 283-291. (doi:10.1038/sj.ijo.0803708)

11 Boivin A, Brochu G, Marceau S, Marceau P, Hould FS \& Tchernof A. Regional differences in adipose tissue metabolism in obese men Metabolism 200756 533-540. (doi:10.1016/j.metabol.2006.11.015)

12 Tchernof A, Belanger C, Morisset AS, Richard C, Mailloux J, Laberge P \& Dupont $\mathrm{P}$. Regional differences in adipose tissue metabolism in women: minor effect of obesity and body fat distribution. Diabetes $2006 \mathbf{5 5}$ 1353-1360. (doi:10.2337/db05-1439)

13 Tchoukalova YD, Koutsari C, Karpyak MV, Votruba SB, Wendland E \& Jensen MD. Subcutaneous adipocyte size and body fat distribution. American Journal of Clinical Nutrition $2008 \mathbf{8 7} 56-63$.

14 Michaud A, Boulet MM, Veilleux A, Noel S, Paris G \& Tchernof A. Abdominal subcutaneous and omental adipocyte morphology and its relation to gene expression, lipolysis and adipocytokine levels in women. Metabolism 201363 372-381. (doi:10.1016/j.metabol.2013.11.007)

15 Farnier C, Krief S, Blache M, Diot-Dupuy F, Mory G, Ferre P \& Bazin R. Adipocyte functions are modulated by cell size change: potential involvement of an integrin/ERK signalling pathway. International Journal of Obesity and Related Metabolic Disorders 200327 1178-1186. (doi:10.1038/sj.ijo.0802399)

16 Franck N, Stenkula KG, Ost A, Lindstrom T, Stralfors P \& Nystrom FH. Insulin-induced GLUT4 translocation to the plasma membrane is blunted in large compared with small primary fat cells isolated from the same individual. Diabetologia 200750 1716-1722. (doi:10.1007/ s00125-007-0713-1)

17 Skurk T, Alberti-Huber C, Herder C \& Hauner H. Relationship between adipocyte size and adipokine expression and secretion. Journal of Clinical Endocrinology and Metabolism 200792 1023-1033. (doi:10.1210/ jc.2006-1055)

18 Jernas M, Palming J, Sjoholm K, Jennische E, Svensson PA, Gabrielsson BG, Levin M, Sjogren A, Rudemo M, Lystig TC et al. Separation of human adipocytes by size: hypertrophic fat cells display distinct gene expression. FASEB Journal 200620 1540-1542. (doi:10. 1096/fj.05-5678fje)

19 Laurencikiene J, Skurk T, Kulyte A, Heden P, Astrom G, Sjolin E, Ryden M, Hauner H \& Arner P. Regulation of lipolysis in small and large fat cells of the same subject. Journal of Clinical Endocrinology and Metabolism 201196 E2045-E2049. (doi:10.1210/jc.2011-1702)

20 DeMartinis FD. Very small fat cell populations determined by a modified osmium tetroxide-urea method. American Journal of Physiology 1985249 C89-C96.

21 Etherton TD, Thompson EH \& Allen CE. Improved techniques for studies of adipocyte cellularity and metabolism. Journal of Lipid Research $197718552-557$

22 Pasarica M, Xie H, Hymel D, Bray G, Greenway F, Ravussin E \& Smith SR. Lower total adipocyte number but no evidence for small adipocyte depletion in patients with type 2 diabetes. Diabetes Care 2009 32 900-902. (doi:10.2337/dc08-2240)

23 Pasarica M, Tchoukalova YD, Heilbronn LK, Fang X, Albu JB, Kelley DE, Smith SR, Ravussin E \& Look AARG . Differential effect of weight loss on adipocyte size subfractions in patients with type 2 diabetes. Obesity 200917 1976-1978. (doi:10.1038/oby.2009.219)

24 McLaughlin T, Sherman A, Tsao P, Gonzalez O, Yee G, Lamendola C, Reaven GM \& Cushman SW. Enhanced proportion of small adipose cells in insulin-resistant vs insulin-sensitive obese individuals implicates impaired adipogenesis. Diabetologia 200750 1707-1715. (doi:10.1007/s00125-007-0708-y)

25 McLaughlin T, Lamendola C, Coghlan N, Liu TC, Lerner K, Sherman A $\&$ Cushman SW. Subcutaneous adipose cell size and distribution: relationship to insulin resistance and body fat. Obesity 201422 673-680. (doi:10.1002/oby.20209)

26 Liu A, McLaughlin T, Liu T, Sherman A, Yee G, Abbasi F, Lamendola C, Morton J, Cushman SW, Reaven GM et al. Differential intra-abdominal adipose tissue profiling in obese, insulin-resistant women. Obesity Surgery 200919 1564-1573. (doi:10.1007/s11695-009-9949-9)

27 Kursawe R, Eszlinger M, Narayan D, Liu T, Bazuine M, Cali AM, D'Adamo E, Shaw M, Pierpont B, Shulman GI et al. Cellularity and adipogenic profile of the abdominal subcutaneous adipose tissue from obese adolescents: association with insulin resistance and hepatic steatosis. Diabetes 201059 2288-2296. (doi:10.2337/db10-0113)

28 Yang J, Eliasson B, Smith U, Cushman SW \& Sherman AS. The size of large adipose cells is a predictor of insulin resistance in first-degree relatives of type 2 diabetic patients. Obesity 201220 932-938. (doi:10.1038/oby.2011.371)

29 McLaughlin T, Deng A, Yee G, Lamendola C, Reaven G, Tsao PS, Cushman SW \& Sherman A. Inflammation in subcutaneous adipose tissue: relationship to adipose cell size. Diabetologia 201053 369-377. (doi:10.1007/s00125-009-1496-3)

30 McLaughlin TM, Liu T, Yee G, Abbasi F, Lamendola C, Reaven GM, Tsao P, Cushman SW \& Sherman A. Pioglitazone increases the proportion of small cells in human abdominal subcutaneous adipose tissue. Obesity 201018 926-931. (doi:10.1038/oby.2009.380)

31 Expert Panel on Detection, Evaluation, and Treatment of High Blood Cholesterol in Adults. Executive Summary of The Third Report of The National Cholesterol Education Program (NCEP) Expert Panel on Detection, Evaluation, And Treatment of High Blood Cholesterol In Adults (Adult Treatment Panel III). Journal of the American Medical Association 2001285 2486-2497. (doi:10.1001/jama.285.19.2486)

32 Michaud A, Drolet R, Noel S, Paris G \& Tchernof A. Visceral fat accumulation is an indicator of adipose tissue macrophage infiltration in women. Metabolism 201261 689-698. (doi:10.1016/j.metabol.2011.10.004)

33 Matthews DR, Hosker JP, Rudenski AS, Naylor BA, Treacher DF \& Turner RC. Homeostasis model assessment: insulin resistance and $\beta$-cell function from fasting plasma glucose and insulin concentrations in man. Diabetologia 198528 412-419. (doi:10.1007/BF00280883)

34 Soula HA, Julienne H, Soulage CO \& Geloen A. Modelling adipocytes size distribution. Journal of Theoretical Biology 2013332 89-95. (doi:10.1016/j.jtbi.2013.04.025)

35 Faust IM, Johnson PR, Stern JS \& Hirsch J. Diet-induced adipocyte number increase in adult rats: a new model of obesity. American Journal of Physiology 1978235 E279-E286.

36 Khan T, Muise ES, Iyengar P, Wang ZV, Chandalia M, Abate N, Zhang BB, Bonaldo P, Chua S \& Scherer PE. Metabolic dysregulation and adipose tissue fibrosis: role of collagen VI. Molecular and Cellular Biology 200929 1575-1591. (doi:10.1128/MCB.01300-08)

37 Lessard J, Laforest S, Pelletier M, Leboeuf M, Blackburn L \& Tchernof A. Low abdominal subcutaneous preadipocyte adipogenesis is associated with visceral obesity, visceral adipocyte hypertrophy and a dysmetabolic state. Adipocyte 20143 197-205. (doi:10.4161/adip.29385)

38 Soula HA, Geloen A \& Soulage CO. Model of adipose tissue cellularity dynamics during food restriction. Journal of Theoretical Biology 2015364 189-196. (doi:10.1016/j.jtbi.2014.08.046)

Received 12 August 2015

Revised version received 9 October 2015

Accepted 16 November 2015 